\title{
CORE COMPETENCIES NECESSARY FOR A MANAGERIAL PSYCHO-EDUCATIONAL TRAINING PROGRAMME FOR BUSINESS TEAM COACHES
}

Authors:

Jeanette E. Maritz ${ }^{1}$

Marie Poggenpoel ${ }^{1}$

Chris P.H. Myburgh ${ }^{2}$

\section{Affiliations:}

${ }^{1}$ Department of Nursing

Science, University of

Johannesburg, South Africa

${ }^{2}$ Department of Education,

University of Johannesburg,

South Africa

\section{Correspondence to:}

Marie Poggenpoel

e-mail:

mariep@uj.ac.za

\section{Postal address:}

Department of Nursing,

University of Johannesburg

PO Box 524, Auckland Park

2006, South Africa

\section{Keywords:}

core competencies;

managerial training;

business coaching; psycho-

educational training;

developing management

Dates:

Received: 14 Feb. 2008

Accepted: 28 Apr. 2009

Published: 19 June 2009

How to cite this article: Maritz, J.E., Poggenpoel,

M., \& Myburgh, C.P.H.

(2009). Core competencies

necessary for a managerial

psycho-educational

training programme for

business team coaches. $S A$

Journal of Human Resource

Management/SA Tydskrif vir

Menslikehulpbronbestuur,

7(1), Art. \#110, 8 pages. DOI:

10.4102/sajhrm.v7i1.110

\section{This article is available}

at:

http://www.sajhrm.co.za

(C) 2009. The Authors.

Licensee: OpenJournals

Publishing. This work

is licensed under the

Creative Commons

Attribution License.

\section{ABSTRACT}

The objective of this research was to explore and describe core competencies necessary for a managerial psycho-educational training programme for business team coaches. The total number of participants in this qualitative research was 30. A purposive and snowball sampling strategy was used. Triangulation was achieved through focus groups, in-depth individual interviews and naïve sketches. Data were analysed through an open inductive approach and descriptive analysis. The results describe core competencies of a business team coach as situated within an Outcomes Based Education framework and relate to the knowledge to be discovered, skills to be mastered and the attitudes to be formed during a managerial psycho-educational training programme.

\section{INTRODUCTION}

Preventing managerial degeneration has become a corporate priority. Van Jaarsveld (2004) warns that, without support and intervention, executives and managers can degenerate personally or their careers can be derailed at enormous cost to themselves, their companies and the economy. Business managers are subjected to more pressure than ever to produce results, yet they are often promoted through jobspecific expertise without the emotional intelligence and work-life balance skills necessary to sustain them (Minor, 1999; Sherman \& Freas, 2004; Van Jaarsveld, 2004).

Developing management is at the heart of Southern African progress (Tuck, 2004/5). There are unique pressures in Southern Africa. The coming together of different cultures in the workplace and the number of unskilled/untrained people who need to be developed quickly represent the most urgent issues. There is also the huge challenge of Acquired Immuno Deficiency Syndrome (AIDS), and there is also the pressure to perform in the context of globalisation (Rostron, 2003).

Fortunately, companies are beginning to realise that executives and managers with years of training are a scarce resource, and that newly promoted managers need to be developed and nurtured. Their ongoing well-being and development are critical strategic concerns. Managerial self-neglect and derailment represent not only a personal tragedy, but also a waste of talent and organisational investment in time, money and human capital.

It is at this point that coaching enters the arena. Coaching has become a popular, mainstream way to develop individuals, executives, managers, leaders, teams and organisations. Research has revealed an across-the-board consensus that coaching is one of the most powerful strategic and tactical weapons open to business today because of its ability to enhance areas of proficiency that are already high, and to establish skills that were previously absent or weak (Bowerman \& Collins, 1999; King \& Eaton, 1999; O'Shaughnessy, 2001; Piasecka, 2001; Redshaw, 2000; Thach, 2002; Tucker, 2007). COMENSA (Coaches and Mentors of South Africa, 2009) defines coaching as a professional, collaborative and outcomesdriven method of learning that seeks to develop individuals and teams, and raises self-awareness, so that specific goals may be achieved.

Coaching derives many of its principles from psychology, especially sport psychology and education (Zues \& Skiffington, 2000). Although the principles of coaching are not new, coaching is relatively new to the world of business. Business coaching has emerged as a crucial activity in supporting individual and team development and performance. It provides new direction in customer satisfaction, productivity and overall organisational effectiveness (Tőnsing, 2003).

In spite of its short history, business coaching is predicted to be one of the growth businesses of the first decade of this millennium (King and Eaton, 1999). Hamlyn (2004, p. 28) describes business coaching as a 'service offering that is most appropriately directed at people in business that have a desire to successfully drive and initiate an environment of sustainable business for tomorrow.' Business coaching provides the gateway to the intellectual and emotional support and development of managers, thus avoiding managerial derailment and preparing individuals to meet the increasingly complex requirements of today's business environment ( $\mathrm{O}^{\prime}$ Flaherty \& Everson cited in Vaida, 2005; Van Jaarsveld, 2004).

While a substantial part of business coaching involves one-on-one coaching, the need for business team coaching is increasing as world-class business organisations shift from I to we. According to Tompkins (1995), world-class organisations will not think in terms of individuals but will focus on teams. Teams have thus become one of the key building blocks of the modern organisation (McBain, 2000).

\section{Rationale}

There are numerous unique challenges facing business team coaching for managers in Southern Africa. One challenge is that Southern Africa is a crucible of multi-cultures, made up of a high number of people who are untrained and unskilled within the business environment and who need to be 
developed (Rostron, 2003). In the past, those who arrived in management positions had spent years being groomed and trained, assimilating the unwritten rules, absorbing the politics, establishing networks of contacts and adjusting to changing power balances (Hillary, 2003).

A new category of manager is now emerging: a manager fasttracked and unschooled in the unspoken, unwritten codes of conduct, with expectations unmatched with the harsh reality of the business environment (Rothgiesser, 2004). Such managers are often naïve, ambitious and hopeful, but also fearful of making mistakes and being found wanting. This leads to needless distress, hurt and frustration, leading to slow personal growth and development.

Another challenge in terms of the coaching profession is that business and team coaching is distinct from other types of coaching and calls for additional competencies and expertise as specialisation areas (Hudson, 1999; King and Eaton, 1999; Skiffington \& Zues, 2003; Zues \& Skiffington, 2000). Core competencies refer to the coaching attributes necessary to perform coaching activities to the standard expected in professional practice. Auerbach $(2005 a$, p. 1) claims it is the concept of identifying and developing particular competencies that leads our clients to make outstanding progress.' This is the root of an effective managerial psycho-educational training programme for business team coaches. In the report of the International Coach Federation (ICF) on The Future of Coaching (2005) the current standards of coaching competence and skills have come under scrutiny. This has been placed at the top of the ICF's strategic planning priorities on an international level. The organisation emphasises that coaching competence and skill sets need to be tied to serious academic research (Auerbach, 2005b). According to COMENSA (2009) a competence tested method forms one of the critical ingredients needed to build a profession.

\section{Problem statement}

Coaching is a young profession and in its infancy in Southern Africa. The coaching profession in Southern Africa does however share international concerns regarding coaching training programmes. Sherman and Freas (2004, p. 84) remark, in the Harvard Business Review, that 'barriers to entry are nonexistent. At best, the coaching certification offered by various self-appointed bodies is difficult to assess, while methods of measuring return on investment are questionable'. Bluckert (2004) adds that there are no real barriers to entry, and also comments on the breadth of backgrounds from which coaches are coming. These include retiring executives, academics, trainers, engineers, senior police officers, teachers, nurses, psychologists, counsellors, psychotherapists and sport coaches. Naughton (2002) believes that most international coaching programmes and imitations do not equip students with sufficient grounding in developmental psychology, interviewing techniques and other elements basic to sound therapy.

In an alarming number of situations coaches who lack rigorous psychological training 'do more harm than good' (Berglas, 2002, p. 87). Lupberger (cited in Naughton, 2002) agrees that intellectual vacuity is prevalent in the field. Locally, professional executive business coaches such as Italia Boninelli (cited in Hamlyn, 2004) state that a number of individuals who profess to be coaches have little practical expertise in business and even less insight into any of the theoretical people skills. Van der Sandt (2004) remarks that the low barrier to entry and the limited number of institutions that provide coaching in South Africa will impact negatively on the quality of coaching training provided. During an interview, David Rock, generally regarded as the leader in global coaching, commented that 'building a team of quality, screened coaches' is both a global and local imperative (Hosking, 2005, p. 9).

Coaching may be a young profession and in its infancy in Southern Africa but the coaching profession can no longer afford to send people into the field as business and team coaches without the agreed upon core competencies and accredited programmes that offer depth in terms of knowledge, skills, attitudes and values. This research addresses the empirical void that exists in terms of described competencies necessary for a managerial psychoeducational training programme for business team coaches in Southern Africa.

The objective of this research was to explore and describe core competencies necessary for a managerial psycho-educational training programme for business team coaches.

\section{Research approach}

\section{RESEARCH DESIGN}

In order to achieve the best, informed results from this research, a qualitative (Creswell, 2003), explorative, descriptive and contextual research approach was employed to explore the core competencies necessary for a managerial psycho-educational training programme for business team coaches. Nelson (cited in Denzin \& Lincoln, 2000) explains that qualitative research is an interdisciplinary, transdisciplinary and sometimes counterdisciplinary field. This multiparadigmatic focus is ideally suited to the multiparadigmatic nature of coaching.

\section{Research strategy}

The unit of analysis for this research was individual business team coaches. The researcher identified coaches who had experience in team coaching within the business context or with managers, CEOs who made use of the services of business team coaches, and managers who participated in business team coaching as multiple sources of information for the focus groups, in-depth individual interviews and naïve sketches.

\section{Research method \\ Research setting}

This research took place within the Southern African context and included participants from South Africa and Swaziland. Various industries were represented, namely the hospitality industry; retail; marketing and sales; travel; and human capital.

\section{Entrée and establishing researcher roles}

Rubin and Rubin (1995) state that qualitative interviews frequently choose interviewees along social networks. In this case, the researcher included interviewees along social and professional networks. The researcher, in qualitative research, is the primary instrument of data collection (Creswell, 2003). In order to prepare himself/herself, he/she has to engage in thorough self-examination as well as master interpersonal and communication skills (De Vos, Strydom, Fouché \& Delport, 2005). To this effect the researcher carried out a personal naïve sketch (Giorgi, 1985) in order to bracket her experience and to create awareness, as she herself is a business and team coach.

\section{Research participants}

The target population in this research was identified as follows: firstly, coaches who had experience in team coaching within the business context or with managers; secondly, Chief Executive Officers (CEOs) who made use of the services of business team coaches; and thirdly, managers who participated in business team coaching. The input of the CEOs in the identification of core competencies was of great importance since they would ultimately employ or make use of the services of the business team coach. Managers were included because they are ultimately the recipients of the managerial psycho-educational training programme. They have experienced business team coaching and their experiences, be they positive or less positive, could give valuable insights into the competencies they expected from a business team coach.

The total number of participants in this research was 30 . Their ages varied from 27 to 60 years. Of the 30 participants, 12 were 
coaches: eight coaches were qualified advanced business coaches, three of which had international recognition. They differed in race, 10 White and two Black, as well as gender, four men and eight women. Five participants were CEOs. Their ages varied from 34 to 50 years, and all were White men. Six participants were general managers. Their ages varied from 35 to 53 years, and all were White men. Seven participants were managers. Their ages varied from 31 to 48 years, and all were Black, four men and three woman.

\section{Sampling}

Purposive sampling (De Vos et al., 2005) was used in order to ensure that specific elements were included in the sample. This approach employs a considerable degree of selectivity. The researcher also used snowball sampling (De Vos et al., 2005), where one member of a group referred the researcher to another member/coach.

\section{Ethical considerations}

In this study the following ethical considerations (De Vos et al., 2005) were taken into account: consent to conduct research was requested and granted through the CEOs of all the business institutions approached. The CEOs acted as gatekeepers for the organisations. Informed consent was obtained from all participants by means of a letter communicating the necessary information pertaining to the research. Confidentiality was maintained and participants were informed of the rationale, recording and safekeeping of audiotaped interviews and transcriptions. Participation was voluntary, and ethical clearance was granted by the University of Johannesburg.

\section{Data collection methods}

Data were collected by means of three focus group interviews (lasting between 45 and 90 minutes; participants ranged between four and seven members), three in-depth individual interviews (De Vos et al., 2005) (lasting between 35 and 60 minutes) and 19 naïve sketches (varying between one to five pages). The researcher's auto-ethnographic naïve sketch was included. To assist in the data collection, the researcher used a field log for field and observational notes (Creswell, 2003) to chronicle her thinking, feelings, experiences and perceptions throughout the research process. Observational notes were made of participants' non-verbal cues, and the dynamics and process between participants in the focus groups and in individual interviews. Some participants were involved in interviews and also submitted naïve sketches.

The question in this research was open-ended and allowed the respondent the opportunity to structure an answer in any of several dimensions (Krueger, 1994). The central question posed to the participants was: 'What are your expectations of a competent business team coach?'

After the central question had been asked, the researcher encouraged the participants to continue talking by using facilitative communication techniques such as probing, paraphrasing, minimal verbal response and summarising (Burns \& Grove, 2005). Data were collected until the sample had been saturated, as evidenced by repeating themes (Poggenpoel, 2000).

\section{Data analysis}

Recorded focus group interviews and individual in-depth interviews were transcribed verbatim and analysed using the descriptive analysis technique of Tesch (Creswell, 2003). The transcribed interviews and naïve sketches were read to gain a sense of the whole. Ideas that come to mind were jotted down in the margin. The most interesting interview was selected and examined to determine what is was about, and to establish the underlying meaning. Again, any thoughts that came to mind were jotted down in the margin. The ideas were converted into topics that reflected their meaning. Similar topics were clustered
TABLE 1

Overview of the themes, categories and sub-categories of the participants' views

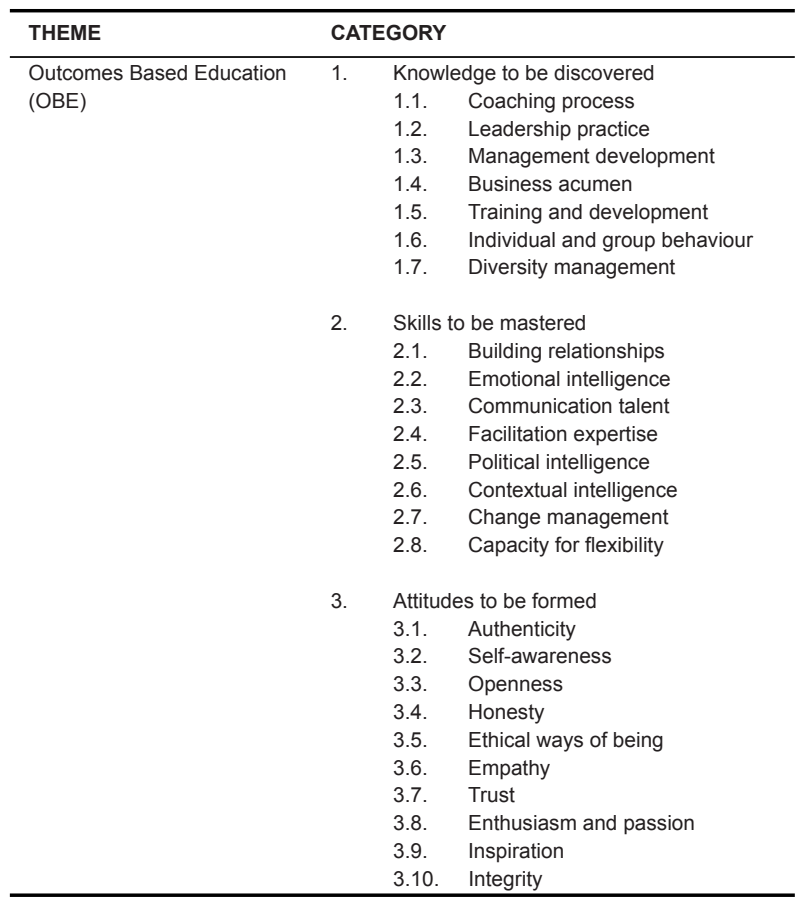

together and placed in columns that were arranged into major topics, unique topics and leftovers. This list was compared to the data, and topics were abbreviated by codes and written next to the appropriate segments of the text. The most descriptive wording for the topics was chosen. The topics were defined and grouped into categories.

A set of clean data was provided to an independent coder who has experience in qualitative data analysis. A consensus discussion was held between the researcher and the independent coder to verify the findings. A literature control provided a framework as well as a benchmark for comparing and contrasting the results (or themes or categories) of this research with other findings (Creswell, 2003).

\section{Strategies employed to ensure data quality}

In qualitative designs, validity and reliability are described through strategies for trustworthiness. This research operationalised the strategies of credibility, applicability, dependability and confirmability as described by Lincoln and Guba (1985). Credibility was ensured through prolonged engagement, triangulation, peer debriefing and member checking. A dense description of the background information and purposeful sampling ensured the transferability of this research. Dependability was maintained through coderecode procedures. Confirmability was established through triangulation and reflectivity.

\section{Reporting}

A qualitative, narrative writing style will be followed in reporting the research findings.

\section{FINDINGS}

Participants identified one central theme, which was divided into three categories. This theme as well as the categories and sub-categories are reflected in Table 1.

The central theme that was identified is as follows. Core competencies necessary for a managerial psycho-educational training programme for business team coaches should fall within an Outcomes Based Education (OBE) approach, where clear statements are made about the knowledge to be discovered 
as well as the skills to be mastered and attitudes to be formed as a result of the business team coach's learning.

The three categories of the above-mentioned theme will now be discussed, supported by direct quotes from the participants.

\section{Category 1: Knowledge to be discovered}

Participants referred to the following essential knowledge: 'coaching process, leadership practice, management development, business acumen, training and development, individual and group behaviour and diversity management.' All seven aspects, each of which is regarded as an essential item of coaching knowledge, are discussed in further detail.

Participants referred to knowledge of the coaching process. A $\mathrm{CEO}$ and a coach explained their views and expectations of the coaching process as follows:

My expectation is focused on the team and the process. Firstly the coach must be experienced in terms of the coaching journey he is taking the team on. The journey must be defined and explained to everybody, so that they understand: we want to coach you towards a specific outcome. The beginning of the session, this is where we stand in terms of the process, this was the type of movements that has taken place in this session, where would we like to be ...

Also weighted by the team coach is: how effective is the team now, what are the shifts? And that will be based on the return on investment exercise ... the coach needs to be trained into literally upfront create with the team a return on investment to say ok, here's the cost value to it and here's the investment value to it, what are we going to get out of it?

Several of the participants mentioned that knowledge of leadership/leadership theories was needed, even though they were somewhat vague as to exactly what knowledge regarding leadership was needed: 'We need something on leadership ...' and

... there is so much said about leadership, a person's definition of leadership is a personal definition. There are assumptions that you make about what constitutes a leader, but a student should be aware of the content of leadership.

Not only should a business team coach be knowledgeable in terms of leadership theories, but he/she should have leadership qualities such as 'seeing the big picture, putting things together, aligning the individual's goals with the company's needs and leading by example.' One management team expressed it as: 'charisma, someone who speaks and gets people going, no matter how difficult they are.'

With regard to the understanding of management principles and development, participants stated that the backgrounds of the business team coaches might be different, but when working with coachees you are:

busy with the profession of the management of a company, you know, if I can't make the shift... I need to teach them to do what they do differently or better... they are busy with the management of companies.

Another coach believed that they need to be competent in management and project management, the latest stuff, not the boring stuff of the past.'

There was no clear consensus amongst the interest groups as to whether expert knowledge of business and industry was needed. Some felt that it was imperative:

He or she must understand the business that I am in, they must have practical business experience over a wide spectrum. He or she must have been where I am, he must have taken the pain that I am taking now.
One coach company stated that '...our coaches are mature, they have been in business, they have been in government, and they know a lot about that stuff.' Others argued that:

A business team coach does not have to be as good as or better than what I am in my business. If we use sporting terms, the golfing coach hasn't been Tiger Woods himself - he happens to coach Tiger Woods. But he understands the business very well ... he has to have an understanding of business principles, not necessarily industry-specific items.

The value of knowledge of training and development is echoed in the following statements made by participants: If the course is about team coaching, you are either going to have to assume that the person has a coaching qualification, if not you are going to have to have a prerequisite of training to align them to coach and then to say we are going to teach the specialisation of business team coaching.

Specific knowledge in relation to training and development were noted as: .... elements of learning styles ... even if it is only for their competitive edge and also to facilitate it with different teams and team members. How do you know that this isn't just becoming just a knowledge session. How do you track and measure ... that it is actually impacting and changing ... and the principles of adult education are essential in a programme for team coaches, they must appreciate that adult learning has a different approach and different assumptions.'

Participants suggested that the business team coach be knowledgeable regarding both individual and group behaviour. With reference to individual behaviour the following aspects were mentioned:

A team coach needs to be equipped in terms of being able to read people and it goes beyond body language. One of the models that would be very good to look at would be the neuro-linguistic model of body dynamics ... you look at all sorts of things like skin texture, movement ... this whole thing of body language ... is really not sufficient. You read people in their metaphor, you read people in their language, their semantics and their body tonality ... so hel she needs to pay attention to that.

Further, it is somebody who can understand different characters, who knows people's behaviour ..., who can understand the way a person behaves. It says in all that person must have done psychology to be able to understand all those things.

Participants discussed the need for business team coaches to be qualified in some area of psychology. One participant reflected after a heated debate:

Maybe it is that rare combination of a person with a psychology background together with a business qualification of sorts, to equip this person to understand how this game of business is being played.

In relation to group behaviour, participants were of the opinion that coaches should also be able to: 'read groups' and 'manage groups'. As one coach put it:

Should there be destructive dynamics within the group, it would be part of my work to pick it up and to find out what the intention is, to then frame the intention that I can return to the outcome, to have a successful company.

Participants highlighted specific aspects of group dynamics in terms of knowledge required: 'You should understand team dynamics and process, and also know the phases groups go through, like storming, norming, all those theories, so that you can understand team dynamics.

Referring to the issue of diversity management a participant called for the team coach 'to understand where people come from ... their culture, their circumstances ...' Another participant added:

Something else that can be addressed is the issue of diversity ... it is through the pulsating heart of diversity that people know what 
happened during a funeral ceremony, how a person is disrespected and they've got person diverse information from each other, rather than hide behind this curtain of culture ...

\section{Category 2: Skills to be mastered}

Following the knowledge dimension, participants commented on the skills that a business team coach should demonstrate. Participants reached consensus, agreeing that the practical application of knowledge should receive more attention in the managerial psycho-educational training programme for business team coaches than the knowledge component: 'The practical is more important than the theory' and 'It is no good if you have the theory but you can't practise it.

The following seven skills were seen as essential: building relationships emotional intelligence; communication talent; facilitation expertise; political and contextual intelligence; and a capacity for flexibility. These skills will now be discussed.

Building effective relationships was seen as a crucial skill. Coaching is about having a relationship with other human beings. In order to have a relationship the business team coach needs 'to have an appreciation for people'. The ability to appreciate people, to manage and maintain relationships requires:

a good business team coach to have emotional intelligence. Hel she needs to be authentic, both within him/her self and with others. Going through the motions of relationships simply won't do. Without emotional intelligence there can be no sustainable growth.

One participant stated: 'It isn't just the IQ - the qualification that you have. It links to self management, if you cannot manage yourself, you cannot manage others, guide others...' In order to demonstrate an effective level of emotional intelligence (EQ) the 'business team coach needs to be self-aware, and know "Who am I? What are my values and beliefs, my personal philosophy? Why am I here?"'. Participants added: 'We need someone who is integrated within himself as a person; you are not going to become a coach if you are, uhm ..., unravelled.' Another added: 'If you bring your crap in there it just all clutters it up. Before you walk in there, you have got to give them a "clean whiteboard".'

Additional aspects of EQ were mentioned that could strengthen the relationship between the business team coach and the coachee:

You must have integrity, you must be ethical. I think it is very important, the ethical stuff, confidentiality, to build trust with the team, to know how to play the game within the organisation.

Another interviewee stated: 'A team coach must have good interpersonal skills - if coaching is about relationships, trust forms the basis.

Having high-quality relationships includes being confrontational when needed: 'I don't want a yes person as a coach; a coach must be able to say "I disagree", be sensibly confrontational and be prepared to say: “No, I don't agree, let's discuss why."'

One CEO mentioned: 'The coach must be able to identify a lack of competency.' Another said:

Unfortunately there will be people who don't fit that, who don't perform, and the coach has to identify those, and has to deal with that in an appropriate manner for the organisation.

Confrontation was juxtaposed by some managers to: 'someone who inspires me to identify my passions and to fulfil my destiny.' Their request was that the coach should: 'focus on our strengths and not our weaknesses; concentrate on the strength so that they override the weaknesses.' They also wanted the business team coach to: '... have a passion for success: a passion to help people think or to be successful.
A need for empathy was voiced when a participant noted:

The coach must be able to share his own pain as well, which helps me feel comfortable that the coach is not perfect either ... they must be open and honest. If they have experienced a similar pain, feel open to relate that to me, because it helps me to feel he is also human and not this perfect person.

Effective communication skills are a function of people's interpersonal effectiveness. Participants agreed that 'we need to look at communication skills, every aspect from the "what" to the "how"...' and 'communication skills are crucial, it is the life blood of coaching.' Participants reflected on the how of communication stating: 'They provide a platform where you can say something that is very important.' Coaching communication should be 'frank and forthright.' There was a need for 'questions that build' and 'forward going questions':

What are we going to do to fix it? How long is it going to take? What resources do we have? What resources do we need? Who's going to champion this? Who is going to follow through? What is the time line? Don't ask why, why is old news, it is defensive and sets up conflict.

Sound listening skills were rated as crucial: 'They need to be able to listen ... we will be free to talk because we know that this person listens to me.' Listening skills were further defined as: '... listening with interpretive capacity...'

Effective communication skills enhanced other interpersonal interactions such as facilitation. Coaching is best described as facilitating. Participants responded that 'Coaching is about facilitating. It is about supporting the recourses of people and the organisation while moving forward to reach the outcome. They make things easier in a sense.' One participant noted that 'it is not so much the content but the process that is involved; they are able to create movement.'

Coaching is best practised by individuals with acute perception and diplomacy, in other words, political intelligence. Participants referred to political intelligence as: '... political savvy because sometimes you as a coach act as a buffer between the company and the team and you must have the skill to deal with that, you must have integrity, you must be ethical.' Another noted that: '... you must be aware of the politics, the games that are played and manage these skilfully.'

All coaching takes places within a certain context and forms part of interpersonal connection. The need for contextual intelligence was mentioned by participants:

I think a team coach would really need to know each person's profile within the team and ask questions in terms of how the different context determines how each person in their particular profile is going to respond within the given context.

One participant viewed contextual intelligence as:

a prime prerequisite as a thinking pattern with team coaches, if we don't think contextually and we can't think in terms of making the fruit salads, then we are busy falling back onto our own expertise, and then we are not busy with the group. Context is a big, big thing. I think we underestimate this method of thinking.

Changes occur continuously in the business world because of the dynamic nature of business and corporations. Thus, business team coaches should be:

... partners in the change process ... there is only one constant in the universe and that is change, it is not whether or not you are going to change, it is how gracefully you engage with the change process. The idea is to get teams to flow, to engage in graceful change.

One manager adds: '... and then manage the change.'

The final skill is the ability to be flexible. 'Here in South Africa you need flexibility. Business team coaches need to be flexible in terms of their roles, the speed of the session, the content.' 
During a reflective conversation at the time of member checking (a technique that consists of continually testing with participants the researcher's data, analytic categories, interpretations, and conclusions), a discussion emerged in terms of the coach's ability 'to tolerate ambiguity'. This links closely to flexibility, as there are often situations where a coaching session, although well planned, can be tainted with aspects of uncertainty and hesitation. It is the successful business team coach who deals with the ambiguity and moves forward without giving up.

\section{Category 3: Attitudes to be formed}

Learning is never only cognitive - attitudes and values go hand-in-hand with intellect. The following attitudes and values emerged from the data and were discussed under EQ: authenticity, self-awareness, openness, honesty, ethical ways of being, empathy, trust, enthusiasm and passion, inspiration and integrity.

\section{DISCUSSION}

The objective of this research was to explore and describe core competencies necessary for a managerial psycho-educational training programme for business team coaches. This research will add value to the coaching training profession in describing the core competencies of business team coaches. This in turn will guide the development of a managerial psycho-educational training programme for business team coaches that is based within the Southern African context (Maritz, 2006).

The results of this research describe the core competencies necessary for a managerial psycho-educational training programme for business team coaches. Core competencies are situated within an OBE framework. In this approach, clear statements are made about the knowledge, skills and attitudes that business team coach learners should acquire as a result of the team coach's learning.

The following essential coaching knowledge was identified: coaching process, leadership practice, management development, business acumen, training and development, individual and group behaviour and diversity management.

Knowledge of the coaching process forms an integral part of the coaching skill set. According to Hall and Duvall (2004), the coach may not be the expert and have all the experience, but he/she knows structure and process and is an expert at coaching. Wild (2001, p. 164) states: 'clearly an understanding and competence in coaching is needed to be developed during the programme.' The basic business team coaching process includes the analysis of the present situation; defining performance goals; eliciting personal, extra-personal and group resources; and the implementation of a plan to achieve the outcome (King \& Eaton, 1999).

The ultimate goal of all coaches is to generate positive transformations in the coachee (Baanders, 2005). Therefore the business team coach is also a leader to a certain extent, because the business team coach leads the coachee or team in a given direction. A solid understanding of leadership theory and research can help a coach achieve success (Goethals, Sorenson \& MacGregor Burns, 2004). It is therefore crucial for a business team coach to be up-to-date with the latest leadership models and best practices.

Hamlyn (2004) recommends that a coaching methodology must be adhered to, and proven practical leadership and managerial skills are essential. Wild (2001) mentions a management qualification as one of the core aspects of the coaching programme at BP, the Oil and Energy Corporation. This, along with the coaching process, training and development, form the basis of their programme. Wherever a business team coach is working in industry, it is also necessary for him/her to understand the following: the culture and politics of the organisation he/she is working in as well as the organisational structure within which he/she is trying to offer coaching. It is also important for the coaches to build rapport, influence others, manage their time and also to manage the main systems in place.

During a programme designed to effectively coach the manufacturing teams at Elida Fabergé in the United Kingdom, the designers asked the question 'What does a business coach really need to know and understand to be effective?' When looking at coaching programmes these seemed to focus on coaching in isolation from the needs of business. The decision was then made to include a management and training/ development component in the programme to improve the coaches' understanding of the culture and politics of the organisation in which they were working, the organisational structure in which they were coaching, and to build rapport and influence others. The measurable and tangible results of adding a management and training/developing component to the coaching programme subsequently included Elida Fabergé being voted as the UK Best Factory 2000, as well as it receiving five other awards (Wild, 2001).

Coaching is about change, and change involves learning. "The essence of coaching comes down to teaching and motivating' Murphy (2005, p. 191). Holliday (2001) and Meyer and Fourie (2004) state that one of the guiding principles for an effective coach is to learn to teach. These authors elaborate by saying that a coach needs to observe how people think and how they process information. In other words they must know the methods for presenting adult education and understand the basic ways people think. Minor (1999, p. 54) and Murphy (2005, p. 179) reiterate that a coach 'shows an awareness of different learning styles'. Not only should coaches be aware of the cognitive domain, they should work with the individual as a whole person.

'Coaches work with the whole person and must be human generalists' (Hudson 1999, p. 17). The bond between a coachee and the coach is of primary importance, and business team coaches need to understand and recognise the difference between people. Improving their psychological skills will aid coaches in their personal development and dealings with coachees.

Stewart, de Kock, Smit, Sproat and Storrie (1996) believe that in Southern Africa knowledge of group dynamics is extremely vital because of the culturally diversified society. Knowing the phases of group development helps the coach's understanding of how groups function, which in turn aids productivity, increases support amongst group members, reduces conflict, improves decision-making and increases lateral thinking and creativity. The same holds for knowledge of diversity management. The business team coach needs an excellent knowledge of the demographics of the organisation's market, and must also identify their own prejudices, stereotypes and biases, and be mature enough to ensure that these do not interfere with the coach/coachee relationship.

Following the knowledge dimension, participants commented on the skills a business team coach should demonstrate. The skills component is, therefore, about the application of knowledge, in other words, what a person can do. King and Eaton (1999) state that while team coaching calls for some special skills, the principles remain the same. Participants reached consensus, agreeing that the practical application of knowledge should receive more attention than the knowledge component. The following skills were seen as essential: building effective relationships, EQ, communication talent, facilitation expertise, political and contextual intelligence, change management and the capacity for flexibility. Skiffington and Zeus (2003) add brainstorming and pursuing helpful alliances to the skills set.

When the business team coach's EQ skills are well developed, he/she has the foundation that helps him/her build strong relationships and communicate effectively. EQ is created and sustained in relationships, and when emotions are acknowledged 
and guided constructively they enhance intellectual performance. Hosking (2005) believes coaches need IQ, EQ and credibility. In today's fast-changing, more open and fluid style of work, a premium is placed on the combination of intellect and EQ, especially when it comes to trusting and teaming with others to solve problems and seize opportunities. Cooper and Sawaf (2000) place EQ on four cornerstones: firstly, emotional literacy, which includes building self-awareness and emotional honesty; secondly, emotional fitness, which includes authenticity and trusting relationships; thirdly, emotional depth, which builds core character and calls forth integrity; and lastly, emotional alchemy, which builds fluid intelligence.

Communication is fundamental to both the coaching process and team effectiveness; as Murphy (2005, p. 192) states: 'If teaching and motivating are essential to coaching, then what could be more important to its success than effective communication.' Experience and success need to be partnered with an excellence in coaching communication. It is vital for a coach to be frank, honest and candid. Great business team coaches tend to be curious and ask penetrating questions. Burdett (1998) believes that all learning starts with a question and that one insightful question is worth many hours telling someone what to do. The literature attests to the importance of listening skills (Cilliers, 2004; Downey, 1999; Holliday, 2001; King \& Eaton 1999; Richard, 1995; Van der Sandt, 2004; Zues \& Skiffington, 2002). Bowerman and Collins (1999) explain that listening takes place on three levels: the head, the heart and the hands. At the head level people listen for thoughts. At the heart level people listen for emotions or feelings expressed through tone of voice, facial expression or body language. At the hands level one listens for the will (energy and commitment). Other communication skills specific to coaching are reported in the literature, and refer to the ability to present ideas convincingly by using a vocabulary rich in metaphors and stories (Hudson, 1999).

Coaching is best described as facilitating and, as such, facilitation is a core competency of a coach (Redshaw, 2000). Facilitation is the skill of interacting with one's audience to draw out their ideas and lead them to new understandings. Business team coaches need facilitation skills to capitalise on the synergy of groups, to gain full support and commitment, manage differences and diversity, and successfully work through conflicts.

Success requires the ability to understand the organisational culture and a willingness to honour the rules of the culture. There are political dynamics that are common to most organisations and those that are unique. An effective business team coach should be skilled at both kinds. This requires an attitude of acceptance of a degree of political game playing (with integrity) (Peltier, 2001). Zues and Skiffington (2002) refer to political astuteness and state that a successful coach is politically nonaligned, although aware of the political manoeuvring that is inevitable in any organisation.

People and organisations are contextually bound. Hargrove (2003) explains that masterful coaching is about intervening in people's context so as to produce a profound alteration in who they are. The author defines context as the background against which people are standing that determines their perception of reality, and what they see as possible and achievable. It is from this background that they draw their identity and formulate their thinking and attitude. According to Priestland and Hanig (2005), context and connection form an integral part of their programme. Evidence of the importance of contextual familiarity is found in business psychology and organisational behaviour. McKenna (2000) points out that apart from team development, with the emphasis on the internal processes of the team, it is important to pay attention to and consider contextual factors, which include the organisation's culture, the clarity of its mission, technology and task design, rewards and performance feedback.

\section{Conclusion}

The world of business is dynamic in nature. Business team coaches should have the necessary change management skills to understand and adapt to change, and also to help the coachee to be able to manage changes in life. Along with the ability to manage change is the value of flexibility. The value of flexibility enables the coach to be able to approach an issue from different perspectives and even to change his/her mind when necessary. Peltier (2001) cautions that a coach who is not flexible will not succeed. Business team coaches are hired and paid to bring a wide ranging, creative, individually designed and compelling repertoire to their efforts.

Learning is never only cognitive - attitudes and values go hand-in-hand with intellect (Van der Horst \& McDonald, 1997). Having the right attitude and living up to the values are of cardinal importance to the coaching process. Several attitudes and values emerged from the data and were discussed under the heading of Emotional Intelligence. These were authenticity, self-awareness, openness, honesty, respect, ethical ways of being, empathy, trust, enthusiasm and passion, inspiration and integrity. Merlevede and Bridoux (2004) include curiosity and willingness to the values they believe need to be instilled. Richard (1995) believes that the coach's personal values will certainly shine through his/her actions.

This author (JEM) feels that someone who is simply following a checklist and going through the motions of being a coach will quickly transmit any scepticism and lack of enthusiasm to the coachee. A business team coach needs to be sensitive to his/her own values and those of others.

Business and team coaching will continue to thrive and gain increased status as a profession. Yet, it is important not to become complacent. In order to adhere to international standards of coaching and deliver ethical services the business team coach should acquire training and experience in the identified business team coaching competencies. It is essential that coach educators interact with various disciplines, both locally and internationally, in order to remain abreast of the latest models, research and practices.

Possible limitations of this study were the restricted number of coaches who have experience in business team coaching, or with managers in Southern Africa. The findings are contextual in nature.

Refinement of the core competencies and training programmes through continuous research is necessary. As business and team coaching is still in its infancy in Southern Africa there is enormous potential for contextual research. Scientific research into the long-term benefits and effect of business team coaching needs to be investigated. Research is needed to identify approaches and styles of coaching that most comfortably accommodate diversity when taking into account the country's diversity in terms of age, race, gender and skills. The durability of behavioural changes associated with business team coaching also needs to be investigated.

\section{REFERENCES}

Auerbach, J.E. (2005a). The College of Executive Coaching Newsletter. Issue 38, May 14

Auerbach, J.E. (2005b). The College of Executive Coaching Newsletter. Issue 41, June 10.

Baanders, R. (2005). Challenges in corporate coaching: Much more than mentoring. Convergence, 6(2), 45-56.

Berglas, S. (2002). Dangers of executive coaching. Harvard Business Review, June, 87-92.

Bluckert, P. (2004). State of play in corporate coaching: Current and future trends. Industrial and Commercial Training, 36(2), 53-56. 
Bowerman, J., \& Collins, G. (1999). Coaching network: A programme for individual and organizational development. The Journal of Workplace Learning: Employee Counselling Today, 11(8), 291-297.

Burdett, J.O. (1998). Forty things every manager should know about coaching. Journal of Management Development, 17(2), 142-152.

Burns, N., \& Grove, S.K. (2005). The practice of nursing research (5th edn.). Missouri: Elsevier Saunders.

Cilliers, F. (2004). Coaching - a systems psychodynamic approach. HR Future, September, 41-42.

Coaches and Mentors of South Africa. (2009). Retrieved April 14, 2009, from www.comensa.org.za

Cooper, R., \& Sawaf, A. (2000). Executive EQ, emotional intelligence in business. London: Texere.

Creswell, J.W. (2003). Research design. (2nd edn.). Thousand Oaks: Sage.

Denzin, N.K., \& Lincoln, Y.S. (Eds.). (2000). Handbook of qualitative research. (2nd edn.). Thousand Oaks: Sage.

Denzin, N.K., \& Lincoln, Y.S. (Eds.). (2005). Qualitative research. (3rd edn.). Thousand Oaks: Sage.

De Vos, A.S., Strydom, H., Fouché, C.B., \& Delport, C.S.L (2005). Research at grass roots. (3rd edn.). Pretoria: Van Schaik.

Downey, M. (1999). Effective coaching. London: Orion Business Books.

Giorgi, A. (Ed.). (1985). Phenomenology and psychological research. Pittsburgh: Duquesne University Press.

Goethals, G., Sorenson, G.J., \& MacGregor Burns, J. (Eds.). (2004). Encyclopaedia of leadership. Thousand Oaks: Sage.

Hall, L.M., \& Duval, M. (2004). Neurosemantic coaching for the next generation executives. HR Future, January, 4-6.

Hamlyn, J. (2004). Executive personal coaching. HR Future, May, 28-29.

Hargrove R. (2003). Masterful coaching (rev. edn.). San Francisco: Jossey-Bass.

Hillary, D. (2003). Executive coaching. HR Future, October, 1011.

Holliday, M. (2001). Coaching, mentoring E managing. (2nd edn.) Franklin Lakes: Career Press.

Hosking, A. (2005). Global trends in coaching. HR Future, March, 8-9.

Hudson, F.M. (1999). Handbook of coaching. New York: JosseyBass.

International Coach Federation (2005). Retrieved November 19, 2005, from www.coachfederation.org

King, P., \& Eaton, J. (1999). Coaching for results. Industrial and Commercial Training, 31(4), 145-151.

Krueger, R.A. (1994). Focus groups. (2nd edn.). Thousand Oaks: Sage.

Lincoln, Y.S., \& Guba, E.G. (1985). Naturalistic inquiry. London Sage.

Lupberger, T. (2002). In J. Naughton (Ed.), The coaching boom. Psychotherapy Networker, July/August, 24-33.

Maritz, J.E. (2006). A psycho-educational programme or team coaches to facilitate the mental health of managers. Unpublished DCur. Dissertation, University of Johannesburg, Johannesburg, South Africa.

McBain, R. (2000). Human resource management. Manager Update, 11(4), September, 19-27.

McKenna, E. (2000). Business psychology and organisational behaviour: A student's handbook. (3rd edn.). Philadelphia: Taylor \& Francis Group.

Merlevede, P.E., \& Bridoux, D.C. (2004). Mastering mentoring and coaching with emotional intelligence. Carmarthen: Crown House.
Meyer, M., \& Fourie, L. (2004). Mentoring and coaching. Randburg: Knowres.

Minor, M. (1999). Coaching for development. California: Crisp.

Murphy, S. (2005). Sport psychology handbook. Champaign: Human Kinetics.

Naughton, J. (2002). The coaching boom. Psychotherapy Networker, July/August, 24-33.

O'Flaherty, C., \& Everson, J. (2005, 19 June). In G. Vaida. Business Times, Careers, p. 1.

O'Shaughnessy, S. (2001). Executive coaching: The route to business stardom. Industrial and Commercial Training, 33(6), 194-197.

Peltier, B. (2001). Psychology of executive coaching. New York: Brunner-Routledge.

Piasecka, A. (2001). Creating champions. Industrial and Commercial Training, 33(2), 69-72.

Poggenpoel, M. (2000). The research interview. In D. Rossouw (Ed.), Intellectual tools. Lynnwood Ridge: Amabhuku.

Priestland, A., \& Hanig, R. (2005). Developing first-level leaders. Harvard Business Review, June, n.p.

Redshaw, B. (2000). Do we understand coaching? How can we make it work better? Industrial and Commercial Training, 32(3), 106-109.

Richard, P. (1995). Coaching for higher performance. Executive Development, 7, 5-7.

Rostron, S.S. (2003). Accelerating performance with coaching. HR Future, June, 4-7.

Rothgiesser, S. (2004). Coaching for better performance. Executive Business Brief, August/September, 52-53.

Rubin, H.J., \& Rubin, I.S. (1995). Qualitative interviewing. London: Sage.

Sherman, S. \& Freas, A. (2004). Wild West of executive coaching. Harvard Business Review, November, 82-90.

Skiffington. S. \& Zues, P. (2003). Behavioral coaching. Sydney: McGraw-Hill.

Stewart, G., De Kock, C., Smit, M., Sproat, B., \& Storrie, G. (1996). Communicating for the professions. Kenwyn: Juta.

Thach, E.C. (2002). Impact of executive coaching and 360 feedback on leadership effectiveness. Leadership $\mathcal{E}$ Organization Development Journal, 23(4), 205-214.

Tompkins, J. (1995). The genesis enterprise creating peak-to-peak performance. St. Louis: Mosby.

Tónsing, T. (2003). Coaching skills training builds sustained superior performance. HR Future, April, 26-29.

Tuck, M. (Ed.). (2004/5). All about human capital management. (2nd edn.). Sandton: WriteStuff.

Tucker, K. (2007). Establishing a mentoring and coaching programme. Randburg: Knowres.

Vaida, G. (2005, 19 June). Business Times, Careers, p.1.

Van der Horst, H., \& McDonald, R. (1997). Outcomes-based education: A teacher's manual. Pretoria: Kagiso.

Van der Sandt, L. (2004). Executive coaching is hot, part two. HR Future, March, 26-28.

Van Jaarsveld, A. (2004). Managerial derailment. HR Future, December, 26-27.

Wild, A. (2001). Coaching the coaches, to develop the teams, to accelerate the pace of change. Industrial and Commercial Training, 33(5), 161-167.

Zues, P., \& Skiffington, S. (2000). Complete guide to coaching at work. Sydney: McGraw-Hill.

Zues, P., \& Skiffington, S. (2002). Coaching at work toolkit: A complete guide to techniques and practices. Sydney: McGrawHill. 